\title{
Rabbi-baldi Cabanillas, Renato. Teoría del derecho. Buenos Aires: Editorial Ábaco de Rodolfo Depalma, 2021 (6 $6^{\mathrm{a}}$ ed.).
}

\author{
Ignacio Aymerich Ojea \\ Área de Filosofía del Derecho \\ Universitat Jaume I
}

Fecha de recepción 01/02/2021 I De publicación: 24/06/2021

El número de publicaciones bajo el epígrafe de "Teoría del derecho" comenzó a incrementarse en España a mediados de los años noventa con la progresiva implantación de la asignatura homónima, a raíz de la extinción de los viejos planes de estudios de 1953 y con ellos de la asignatura "Derecho natural". No ha sido así en Argentina, donde la tradición de estas publicaciones es más prolongada. Cabe citar, entre otros, a Álvarez Gardiol (Introducción a una teoría general del derecho, de 1975), Vernengo (Curso de teoría general del derecho, de 1976), Nino (Introducción al análisis del derecho, de 1980), Zuleta Puceiro (Teoría del derecho, de 1987) o Marí (Materiales para una teoría crítica del derecho, de 1991).

Tampoco es equivalente la caracterización de las posiciones doctrinales en España y Argentina que allí, a grandes rasgos, se divide en analíticos, críticos e iusnaturalistas. Dentro de estos últimos, Mario Alberto Portela distingue una rama más metafísica, ligada a la ortodoxia católica, y otra menos dogmática, formada en diálogo con Rawls, Dworkin, Alexy, Finnis y las teorías de la argumentación ligadas a la concepción tópica del derecho. En esta última línea, la obra de Rabbi-Baldi ocupa una posición de referencia. La obra tuvo una primera edición en 2008 a la que han seguido otras en 2009, 2013, 2016, 2019 y esta que nos ocupa. El hecho de haberse ya agotado las 5 primeras y que se presente ahora esta edición corregida y ampliada es una muestra de la buena acogida que ha merecido. Igualmente lo es que la publicación haya obtenido el premio Accésit de la Academia Nacional de Derecho y Ciencias Sociales en 2010 o que el libro de $\operatorname{casos}^{1}$ que acompaña a este tratado contase en 2016 con la presentación de Robert Alexy (con quien el autor y junto con Juan Pablo Alonso comparte la coordinación de la obra Argumentación, derechos humanos y justicia, de 2017).

\footnotetext{
${ }^{1}$ Lecciones de teoría del derecho. Una visión desde la jurisprudencia constitucional. Ábaco. Buenos Aires, 2016.
} 
Renato Rabbi-Baldi es profesor titular regular de teoría general y filosofía del derecho en la Universidad de Buenos Aires, así como profesor en la maestría de magistratura judicial de la misma universidad. Une su experiencia de más de treinta años de docencia en esta materia a la de Juez de la Cámara Federal de Salta y, anteriormente, de secretario letrado de la Corte Suprema. Es también miembro, desde 2012, de la Academia Nacional de Ciencias Morales y Políticas. Obtuvo su doctorado en España y posteriormente amplió estudios en Alemania. Tanto en esta obra como en sus anteriores publicaciones muestra un destacable manejo del pensamiento clásico en el ámbito de la filosofía jurídica.

El libro se estructura en siete capítulos que responden a cuatro grandes líneas temáticas, dedicadas respectivamente a los fundamentos del derecho, las fuentes y el derecho como sistema, la interpretación jurídica y la teoría de la justicia. La primera de ellas (capítulos I a III) trata de sustentar la realidad jurídica sobre el concepto de persona definido a partir de un examen histórico, filosófico, conceptual y legislativo-jurisprudencial. No ignora el autor que vincular los caracteres identificativos del sistema jurídico con una específica concepción material de la justicia como esa es uno de los principales puntos de fricción entre iusnaturalismo y positivismo, por lo que aborda a continuación la polémica entre ambas posiciones. Concluye con una reflexión que trata de superar tradicionales malentendidos en este debate y que aspira a recibir aportaciones de ambas corrientes. Siguiendo a Llompart postula una tercera vía que abandonaría el modelo iusnaturalista tradicional, defensor de unos principios de justicia universales e inmutables, en beneficio de un ámbito de indisponibilidad que mantendría al derecho a salvo del establecimiento de normas contrarias a unos elementales principios de justicia. Pero estos principios se reconocen históricos, mudables. Se trata así de fundamentar el derecho en la síntesis de elementos que proceden de la naturaleza humana, la naturaleza de las cosas, el acuerdo y la convención positiva, fundamentación que en ciertos aspectos recuerda a Gény y en otros a Pérez Luño. Más allá del grado de adhesión que el lector pueda tener hacia este tipo de argumentos debe reconocerse al autor el esfuerzo por aportar solidez argumentativa a esta clásica cuestión.

La segunda parte está dedicada las fuentes y al derecho como sistema y aunque cabría esperar que esta parte se correspondiese más con las clásicas cuestiones de la teoría general del derecho tal como se plantean habitualmente en los manuales de uso en contextos como el nuestro (unidad, validez, plenitud, coherencia, jerarquía de fuentes, etc.), mantiene el hilo argumental de la primera parte al tratar de mostrar las limitaciones del positivismo y la integración del derecho natural en el sistema jurídico. 
La tercera parte expone la interpretación jurídica como una constante tensión entre "cetética" y "dogmatica" (muy al hilo de los argumentos de Viehweg sobre la ciencia jurídica orientada al problema más que al sistema), para lo cual hace una interesante reconstrucción histórica de los modelos de argumentación desde la compilación de Justiniano hasta el Movimiento del derecho libre. La aportación en la parte de la teoría de la justicia rescata argumentos de Aristóteles, Sócrates, Ulpiano o Santo Tomás pero no entra a debatir las cuestiones que caracterizan a este ámbito desde Rawls en adelante, así que elude pronunciarse sobre las tesis de Walzer, Habermas, Brian Barry, Taylor o MacIntyire, por citar sólo a algunos.

Una de las aportaciones más relevantes de esta "Teoría del derecho" es que somete las afirmaciones realizadas en el plano teórico a un contraste permanente con la argumentación desarrollada por la jurisprudencia, especialmente la de la Corte Suprema argentina. Cumple así con creces lo que el autor declaraba ya en la introducción de la primera edición, cuando afirmaba que la obra aspira a responder a cuatro notas: histórica, empírica, analítica y normativa, y explica que lo empírico viene dado porque la teoría del derecho es, precisamente, del derecho, por lo que no puede desvincularse de sus fuentes, especialmente de su ámbito de mayor concreción: la jurisprudencia. Es tal vez esta última aportación la que más puede interesar al lector español, al tener a su alcance con esta obra una oportuna selección de casos recientes de la argumentación constitucional argentina y una serie de debates ligados a reformas legales recientes (reformas de la legislación civil y comercial o sobre interrupción del embarazo, por ejemplo).

Siguiendo la opinión de Portela decía al comienzo que la obra representa un esfuerzo renovador en el pensamiento iusnaturalista al abrirse al diálogo con otros desarrollos contemporáneos de la filosofía jurídica. En el balance final hay que decir de la obra que es muy loable la aproximación a desarrollos contemporáneos del pensamiento jurídico pero no deja de estar anclada a posiciones que dejan poco margen a la actualización. El autor se manifiesta en varias ocasiones acreedor a la teoría de Javier Hervada, a quien considera su maestro y que, dicho sea de paso, es el autor más veces citado a lo largo del texto. Hervada, canonista que fue de la Universidad de Navarra, sostenía que "todo derecho existe en su fundamento de igual manera y con igual intensidad con independencia de la historia" (tomado de Introducción crítica al derecho natural. Eunsa. Pamplona, 1980. p. 100). Y Rabbi-Baldi, glosando la idea, afirma que "toda vez que existe la naturaleza humana entendida de la manera que se la ha reconocido ("metafísica" por oposición a meramente "física"; finalista y no determinista), es claro 
que toda persona es acreedora [...] de bienes o títulos inherentes y que, por tanto, permanecen en ella por el solo hecho de ser tal" (p. 280). 